\title{
Parental involvement in sharing childcare activities among agricultural labourer households
}

\author{
DIBYAPRAVA PRADHAN
}

Received: 04.09.2014; Revised: 07.11.2014; Accepted: 22.11 .2014

Author for correspondence: DIBYAPRAVA PRADHAN Department of Human Development and Family Studies, College of Home Science, Orissa University of Agriculture and Technology, BHUBANESWAR (ODISHA) INDIA

Email : dibyapradhan@rediffmail. com
ABSTRACT : In the Indian family setting, the sharing of childcare responsibilities between husband and wife is not widely accepted. Parental role and their involvement in childcare are very important for the overall development of the child. For the first time, an attempt has been made to quantify the percentage of involvement of both mother and father in childcare activities separately. A study was conducted on 160 agricultural labourer households having at least one child in the age group of 1-5 years from 8 villages randomly selected from four blocks, which were purposively selected from four districts of Orissa. Majority $(78.05 \%)$ of mothers were found to be involved in cleaning baby's mouth whereas least (3.65 $\%$ ) in getting play materials for the child. As high as 44.27 per cent fathers were involved in giving moral teaching to the child and a minimum $(1.04 \%)$ in introducing pre lacteal feed. The percentage of share of fathers, mothers and other relatives in childcare was 19.92, 52.84 and 27.24, respectively indicating that mothers took care of their children more than two times than that of fathers and even members other than parents has more involvement than the fathers.

KEY WORDS: Parental involvement, Childcare activities, Agricultural labourers

— HOW TO CITE THIS PAPER : Pradhan, Dibyaprava (2014). Parental involvement in sharing childcare activities among agricultural labourer households. Asian J. Home Sci., 9 (2) : 542-545. 